\title{
A MEMÓRIA COMO ESPAÇO FANTÁSTICO
}

\author{
Ana Luiza Carvalho da Rocha e Cornelia Eckert \\ Banco de Imagens e Efeitos Visuais e Navisual PPGAS - UFRGS, Brasil
}

No desvendamento destas diferentes modalidades das sociedades humanas configurarem o controle simbólico do tempo, as ciências humanas (sobretudo a antropologia e a história) trataram, mais recentemente, de desconstruir o tempo por intermédio de sua dimensão interpretativa, seja como espaço de construção de uma inteligência narrativa que encerra a experiência de duração ${ }^{1}$ reino da imaginação criadora; seja como fenômeno que participa do trajeto do imaginário e de sua topologia fantástica, nos arranjos que engendra entre vida e matéria ${ }^{2}$.

O tom interpretativista pode ser considerado um denominador comum que atravessa as reflexões de inúmeros intelectuais e filósofos contemporâneos que, hoje, revisitam a noção de memória como elemento fundante do processo de construção da figura primordial do homem, tratando-se aí de reconhecer e compreender as tradições históricas, sociais e culturais que carregam e marcam de suas configurações. Assim, qualificam-se as noções de memória a partir do contexto em que são geradas (nos termos de genealogia e arqueologia) e ressaltam-se os aspectos dialéticos, contraditórios e conflituais na forma como emergem no interior das produções do conhecimento humano.

Neste sentido, a força interpretativa reconhecida à memória como espaço de construção do conhecimento, confere a ela o estatuto de uma linguagem de símbolos que reúne uma ação inteligente do sujeito humano sobre o mundo, fragmento do ato de pensar no qual se pretende descortinar o momento intangível de enlaçamento, a um só tempo, do "eu" e do mundo. Uma vez que se atribua ao fenômeno da memória o instante fugaz em que a linguagem humana estrutura o pensamento, através da interpretação de um princípio de causalidade (formal material), todo o esforço será de compreender a sua acomodação/assimilação ao arbítrio de uma gramática simbólica, a cultura.

A memória como espaço fantástico, lugar de extraversão e introversão de uma linguagem arbitrária de símbolos, coordenada, no plano da imaginação criadora, por esquemas de pensamento, apela, portanto, para os diferentes procedimentos interpretativos-

\footnotetext{
${ }^{1}$ Cf. RICOEUR, 1994 e 1979.

2 Cf.G. DURAND, 1984, cuja obra segue a linhagem direta dos estudos bachelardianos sobre a duração, cf. G. BACHELARD, 1989.
} 
narrativos que dão sentido aos arranjos entre vida e matéria, reunindo-as de forma inseparável.

Em Benjamin (1892-1940), por exemplo, observa-se o valor da narração como lugar para se pensar a memória moderna ${ }^{3}$. Embora invista no substrato racional que subjaz este fenômeno, esse autor reúne aos atos da razão, outras instâncias que a subvertem, nos jogos da memória, como as instâncias do sentimento, da intuição e do movimento ${ }^{4}$. Uma vez que se reconheça os limites metodológicos da separação ontológica entre vida e matéria e o paroxismo que encerram os atos humanos, não se trata mais de refletir sobre a memória apenas sob os efeitos do ato de rememorar,.

$\mathrm{Na}$ trilha de um bergsonismo mais instaurador, Benjamin considera a sociedade na relação com a experiência histórica, mostrando que o conceito de duração em Bergson, ao se afastar da história, suprimindo a morte, exclui a possibilidade de acolher a tradição ${ }^{5}$. Seguindo as pistas deixadas em aberto por aquele autor, Benjamin ultrapassa a noção de memória promovida pelo pensamento bergsoniano ao criticar o aspecto de uma imaginação tímida à ela atribuído, beirando o ideal de dedução absoluta do mundo das coisas.

Ao longo das imensas rupturas e descontinuidades provocadas por revoluções tecnológicas e científicas do séc. XX, dos quais somos tributários em nossa "arte de pensar" o mundo e o tempo, não é ao acaso que se constata que os estudos da memória, ao pautar-se por uma reflexão sobre a vida e a matéria, atribuem ao ato de narrar um valor simbólico de construção de sentido de uma história vivida entre tantas outras para serem vividas. Neste ponto, o tema do "fantasma do esquecimento", tão caro a obra de Benjamin, anuncia, de forma comovente, o sentimento de "crise da civilização" que se manifesta na crise epistemológica das "ciências do homem" geradas no mundo contemporâneo.

\section{O fim da arte de narrar e os jogos da memória, a mística das imagens}

Sob os efeitos do desmoronamento dos mapas intelectuais do séc. XIX e da perda de sua aura, o pensamento benjaminiano teve o mérito de confrontar-se, ainda que sob a atmosfera do desencantamento do mundo, com o dilema do esquecimento ${ }^{6}$. Segundo Benjamin, a situação agonizante das tradições e a morte da narrativa, torna-se uma

\footnotetext{
3 Os textos de W. BENJAMIN utilizados na composição deste artigo foram "Sobre alguns temas em Baudelaire". In: Charles Baudelaire, um lírico no auge do capitalismo. Obras escolhidas volume III. SP, Ed. Brasiliense, 1990, "O Narrador" e "O Surrealismo". In: Coleção Os Pensadores, São Paulo, Ed. Abril, 1978.

${ }^{4}$ Cf. M. SANTOS 1993:83.

${ }^{5}$ Cf. BENJAMIN, 1990: 137.

${ }^{6}$ Segundo, S. H. BORELLI, 1992: 90: "Para Benjamin, portanto, onde existe experiência restaurada, existe a conjunção inevitável entre passado individual e referenciais coletivos".
} 
ameaçauma vez que a perda significativa da transmissão de experiências que dizem respeito à compreensão e interpretação do passado, cujo ato de rememoração resgata, tende a sobrepujar a angústia do esquecimento, numa orgulhosa inscrição das obras humanas para além das funções sociais que cumprem e os lugares históricos que ocupam.

Narrativa versus informação, a oscilação do tempo versus o instante do acontecimento, o pensamento benjaminiano aponta para a perda do compromisso humano com um tempo que se exaure e o lugar da narrativa como sua força de germinação ${ }^{7}$. Abreviar a narrativa, sobrepujá- la com uma historiografia na intenção de atingir "o plano divino da salvação", eis a perda da força plástica que o "pensamento da morte sofreu na consciência comum", reduzindo-se a "imediatez da experiência", o rosto da morte acaba referido ao mundo dos vivos, privando-se a memória de sua força narrativa, justamente esta que lhe autoriza, em parte, reparar os ultrajes do tempo ${ }^{8}$. Ou, nas palavras do mestre, "a memória é capacidade épica por excelência".

Torna-se relevante, se ressaltar que foi justamente a tradição romântica, navegando no sentido contrário do tempo linear e progressista propagada pela pedagogia ocidental da Era Moderna, que sustentou a tese da complexificação do caráter social e psíquico do fenômeno da memória, ao realocar, nos jogos da memória, a possibilidade de construção/ reconstrução da identidade social ao mesmo tempo que nela se exercita a condição ideologicamente instauradora da identidade pessoal.

Em fins do séc. XIX, a experiência proustiana romântica do "tempo reencontrado"”, emergindo da "estratificação de múltiplas renarrações", nos termos benjaminianos, já desfazia as teses reducionistas que não conseguiam atingir, com suas teorizações, as curvaturas do tempo da memória, no interior da qual é possível, ao sujeito humano, sempre e eternamente, reintegrar um tempo perdido, reconciliando-se com a vida, em detrimento da morte. No âmbito das reflexões filosóficas do intimismo romântico, em pleno momento de expansão dos impérios coloniais, o tema recorrente é a "amnésia coletiva", apostando-se que os jogos da memória, aliando razão e sentimento, num duplo movimento entre seres e coisas, possa servir de garantia ao processo de re-integração do psiquismo humano ao mundo social ${ }^{10}$. Na consciência romântica do séc. XIX, na contramão das consolidações positivistas da história

\footnotetext{
${ }^{7}$ Cf. W. BENJAMIN, "O narrador", 1978: 64: "A idéia de eternidade teve na morte, desde sempre, sua fonte mais forte."

${ }^{8}$ Cf. G. DURAND, 1984:275.

9 Segundo L. F. DIAS DUARTE 1983, Proust, “através da introspecção do intimismo literário da tradição romântica, partindo do recurso à memória individual linear para fragmentá-la ou para retotalizá-la em um universo coetâneo de significação".

${ }^{10}$ Cf. M. SANTOS, 1983: 83.
} 
que substituíram a velha ordem teológica e metafísica, os meandros cavernosos da memória evocam a união do homem com o seu destino mortal, contrapondo-se às imagens messiânica e progressista do tempo, permitindo que a Era moderna, em meio às suas transformações, "permaneça humana"11.

Não é de se estranhar, portanto, que os símbolos intimistas aplicados ao fenômeno da memória atinjam um espaço legítimo de reflexão, no alvorecer do século $\mathrm{XX}$, com a crise dos impérios colônias, provocando, por seu turno, o deslocamento das fronteiras entre uma metafísica idealista ou um positivismo exacerbado. Em Baudelaire, Bergson, Benjamin, Proust $^{12}$, a memória assume um papel redentor da queda moral da figura humana presente ao ideal prometéico do Ocidente moderno, uma vez que por seu intermédio as situações e os seus valores iniciais são re-invertidos, numa progressão dramática, algumas vezes, quase épica.

De fins do séc. XIX até os dias de hoje, o sensorialismo e os trabalhos de miniaturização do mundo atribuídos aos jogos da memória, assim como a viscosidade confusional designada, no presente, ao lugar das lembranças do passado, despontam, via de regra, como valores antagonistas à destruição, em escala mundial, de povos e culturas, logo após a Primeira Grande Guerra, ao aniquilamento de cidades inteiras e dos lugares de enraizamento de inúmeras comunidades, provenientes de atos militares, durante a II Guerra Mundial, aos avanços científicos e tecnológicos aplicados a corrida armamentista, em escala planetária, nos anos subseqüentes da Guerra Fria, ao desmoronamento de antigas fronteiras geopolíticas dos Estados-Nações, etc. Os estudos da memória assumem, neste curto espaço de tempo, o lugar privilegiado de reflexão sobre as curvaturas que o tempo possibilita quando, sujeitas a um processo de globalização, as sociedades e os grupos humanos reascendem antigas paixões e tradições locais.

Portanto, no interior da erosão de um regime heróico da imagem, os estudos da memória, em particular com o bergsonismo, tornam-se propícios ao "reinvestimento mitológico" onde não só triunfam os valores e as imagens da intimidade, o "eu profundo" mas despontam os temas da alteridade entre vida e matéria e da interiorização da inseparável dualidade de imagem-hábito (eu superficial) da imagem-lembrança (eu profundo).

Ao longo do séc. XX, o confronto entre presente e passado, reunidos num mesmo

\footnotetext{
${ }^{11}$ A propósito, ver a obra de G. Durand, 1979, em especial, o Cap. VIII, Les mythes et symboles de l'intimité au XXIe siècle.

12 O que Proust e Freud irão encontrar um século mais tarde, a tragédia do desenvolvimento Fausto de Goethe (1770-1831) elabora quando Fausto recupera no som dos sinos da Páscoa, a lembrança da infância que o fazem chorar com alegria e enternecimento. Como o explica Marshall Berman "Como um náufrago que se ergue à tona para ser salvo, Fausto inadvertidamente se abriu a toda uma dimensão perdida do seu próprio ser, entrando em contato com fontes de energia capazes de renová-lo.” BERMAN 1986: 45.
} 
espaço pelas curvaturas do tempo propiciadas pelas novas tecnologias das redes eletrônicas e digitais, nas trilhas da unidimensionalidade da grande aldeia global, tem impulsionado as ciências humanas ao reconhecimento das rupturas de uma temporalidade que parecia linear, contínua e progressista, um tempo múltiplo onde os jogos da memória sugerem, a todos quanto deles participam, uma relação reflexiva com a trajetória histórica do sujeito e do coletivo que professam.

Progressivamente, critica-se, uma concepção que prioriza a causalidade histórica para o estudo da memória, agora, mais do que antes associado a uma "longue durée", que o tempo está contido na "imagem dialética"14 entre "despertar" e "recordar". Ao passado é atribuído um estatuto de conhecimento a partir de um presente conceitualizado, sendo a prática da rememoração re-situada no interior da narrativa dos sujeitos sociais.

Rememorar transforma-se, assim, numa força reinventiva do tempo do mundo no qual gravita toda a sociedade humana, agora numa escala de vida planetária. As teses vitalistas ou fisicalistas de outrora, não mais se sustentam, não sendo mais generalizável para sociedades e homens que encontram, justamente nas dobras do tempo, o sentido para o presente, relacionado-o ao contexto original onde tudo parece ter sido gerado. A memória adquire densidade e espessura, referida que está as suas camadas de duração, a base de tudo sobre o qual se erigiu a humanidade em sua capacidade refletir frente ao que lhe é transmitido socialmente, ao mesmo tempo "alma santa", "vítima" e "carrasco".

Diferentemente do que, nos séculos precedentes, se poderia pensar uma reflexão sobre tempo, memória e duração, a sociedade contemporânea se debate com a herança dos paradigmas que geraram a noção de pessoa moderna, os postulados do individualismo e "sua epopéia humanitária e progressista"15. O ato de rememorar, não são apenas ações que expressam uma faculdade psíquica de enunciados provenientes da razão (esta, como a técnica e a ciência, sofrendo duros golpes).

A tese que aqui se apresenta, a memória como consolidação de um tempo ondulante e lacunar, fenômeno complexo e profundo que recria, por sua vez, uma hierarquia na essência do ser, e que não pode ser reduzida a pura intuição do tempo, pois este lhe escapa no triunfo de um tempo reencontrado, logo negado, tem um débito inestimável por nós ainda não suficientemente tributado ao pensamento bachelardiano.

Ao se conceber a memória como poder de organização de um todo a partir de um

\footnotetext{
${ }^{13}$ A respeito ver LE GOFF, J. NORA, P, 1990.

${ }^{14}$ Cf. comentários de BOLLE, 1994. "a imagem dialética não se opõe em termos absolutos à imagem onírica, mas guarda dela um resíduo mítico".

${ }^{15}$ Ver a respeito os comentários de G. DURAND, 1979, Cap. Le XX ${ }^{\mathrm{e}}$ siècle et le retour d’Hérmes.
} 
fragmento vivido, como a pequena Madalena do Temps perdu, a vida não é devir cego, mas capacidade de reação e de regresso, pois um mero fragmento de existência pode resumir e simbolizar a totalidade do tempo reencontrado ${ }^{16}$.

\section{A memória e seus duplos, metáforas de um universo negro}

O tratamento conceitual revisitador adotado por nós, neste artigo, menciona alguns dos dilemas filosóficos contemporâneo que colocam o tempo, ora como um dado da intuição, jogando mais ao lado do instinto que da inteligência, ao perscrutar a vida e a matéria através de uma "metafísica um tanto arriscada" (característica peculiar ao pensamento bergsoniano); ora, ao inverso do anterior, o tempo se define como uma forma a priori de sensibilidade e do entendimento, anterior a experiência mas que nela se manifesta (nos termos de uma metafísica kantiana), tempo como anterioridade lógica de estruturação da experiência ${ }^{17}$.

Neste tópico, trata-se aqui de outra pergunta: a Antropologia, em suas tentativas para entender o paradoxo criador que é o homem, atinge as condições epistemológicas adequadas, na linha de um pensare doble, para operar com conhecimento da memória à partir de uma idéia de tempos múltiplos e sobrepostos? Quais as funções que cumprem as duas premissas básicas desta matriz disciplinar - a comparação e a relativização - na resolução positiva deste questionamento?

Para se responder adequadamente tal ordem de indagação é necessário admitir a ambigüidade paradigmática e multiplicidade antagonista que é o homem, abandonando-se a uma necessidade de explicação causal única. A resposta possível só pode ser encontrada levando-se em conta o campo da investigação antropológica, eternamente construído para dar conta da compreensão, ao mesmo tempo, universal e singular das experiências humanas, e onde o próprio fazer antropológico se situa.

Todos os antropólogos conhecem, na linha do anthropological blues, o desafio de traduzir, nos termos da sociedade ocidental (da linearidade da escrita, e do discurso científico, não necessariamente cientificista), as variadas modalidades simbólicas de controle do tempo apresentadas pela diversidade das sociedades humanas ${ }^{18}$. Como, por exemplo, tornar inteligível a interpenetração do acontecimento e da estrutura para os antropólogos que já

\footnotetext{
${ }^{16}$ Cf.G. DURAND, 1979.

17 A propósito ver N. ELIAS, 1996.

18 Segundo G. DURAND, 1979, é necessário inverter os termos da famosa prescrição délfica, "Conhece inicialmente os deuses, conhece teu universo cósmico e cultural e tu te conhecerás a ti mesmo", degradada numa interpretação de neutralidade axiológica progressiva e unidimensional do sujeito do Cogito, para outra modalidade de frase: "Conhece-te a ti mesmo, e tu conhecerás o cosmo e os deuses".
} 
habituados à axiomática separação entre história e mito $?^{19}$

Inúmeros estudos etnográficos tratam das estruturas espaço-temporais de sociedades tradicionais cotejando-as com aquelas presentes na civilização ocidental judaico-cristã, habituada ao divórcio entre Fé e Razão, oriundo da escolástica medieval, e à díade antagonista Alma e Corpo, produto do cartesianismo. Tais estudos etnográficos tem revelado que a base da "personalidade" œidental reside justamente na separação do mundo e do eu, sendo a memória freqüentemente referida como um fenômeno que não participa do mundo, não tem nenhuma "espessura", nem "densidade relativa à permeabilidade entre as esferas coetâneas do humano e do divino" 20 . Separando o "eu superficial" e o "eu profundo", ou reunindo-os, tal qual o bergsonismo, para melhor separar o "eu profundo" do "mundo das coisas", o modelo de unidade do tempo se restringiria ao encadeamento subjetivo do tempo existencial, na vacuidade do "eu penso", que se torna histórico, e de um espaço regular e monótono, de tipo euclidiano.

Entretanto, em sociedades tradicionais, nas civilizações de práticas não-ocidentais, o tempo é vivido e pensando através do continuum da memória, salvaguardado na tradição, pelo qual o mundo e o cosmos emitem valores, e o "eu", é construído e continuado, em suas camadas superficiais ou profundas, a partir de seu pertencimento, múltiplo e diverso, à tal ordem de criação.

Para o "homem da tradição", diferentemente do "homem da civilização", rememorar traduz-se por uma atitude espiritual que envolve diretamente rituais cotidianos que são fundamentais para que a ameaça de esquecimento seja dissipada ${ }^{21}$. Atos rituais (sagrados) e atos cotidianos (profanos) são em si mesmo, unos, configurando-se a memória como enthousiasmos ${ }^{22}$.

Sem dúvida, esta perspectiva de se viver o tempo aderindo ao ritmo de sua própria matéria ondulatória, choca-se com o processo de construção e demarcação de uma nova temporalidade e épistémè, das quais muitos de nós, antropólogos, para o pior ou o melhor, somos herdeiros bastardos, ou seja, a épistèmé clássica, responsável pela "desfiguração da

\footnotetext{
${ }^{19}$ Cf. RAMOS, 1990:179.

${ }^{20}$ Cf. Jean-Pierre Vernant apud, L.F. DIAS DUARTE, op. cit..

${ }^{21}$ M. ELIADE, em sua obra clássica, Le mythe de l'éternel retour, 1982, analisa aqui o tempo como sagrado por sua qualidade de Eterno Retorno, conquistado na permanência dos rituais que eternizam o presente por pressupostos cosmológicos.

${ }^{22}$ Segundo L.F.DIAS DUARTE, op. cit., p.31:“A 'memoricidade' é assim em primeiro lugar 'possessão' enthousiasmos. E enquanto 'possessão' é também - repetindo a dualidade das experiências religiosas 'iniciação', treinamento ritual, organização 'litúrgica'”.
} 
visão do homem" ${ }^{23}$ no Ocidente judeu-cristão, mas igualmente responsável pelo nascimento e pela gênese da concepção de pessoa moderna.

Da concepção puramente cosmológica do movimento temporal tal qual apresentada por Aristóteles, revistas nas aporias de Santo Agostinho, as quais são retomadas, mais de um século depois, no dogmatismo doutrinário de Santo Tomas de Aquino, e realçadas por Kant, à luz do idealismo das formas a priori de entendimento e de sensibilidade, ao racionalismo positivista que impregna a civilização ocidental, transmutam-se novos valores epistêmicos que insistem na universalização da temporalidade cristã. A base deste movimento contínuo de "catástrofes metafísicas" reside justamente na re-significação da imagem do homem através da conversão progressiva de um eu múltiplo e diverso, e suas camadas de duração, à forma vazia do Cogito, à vacuidade da fórmula "Eu penso... logo existo". Portanto, é na abordagem íntima do tempo e a conceitualização do tempo íntimo que desponta, na qualidade de sistemas filosóficos, a gênese da pessoa moderna.

Na tradição ocidental judaico-cristã, o tempo que narra a entrada de Deus na história reconfigura o tempo por meio de conectores específicos (calendário, eras, séculos, datas, etc), e à medida que toma sua forma na figura do homem racional e histórico, sede da consciência e do Cogito, que pretende subjugar (e ocultar) a figura tradicional do homem, cresce e se avoluma "uma espécie de anti-história" ${ }^{24}$ que se espelha na ordem dominante do mito do progresso e nas teses evolucionistas daí derivadas, ordenadas segundo "os quadros vazios, regulares e monótonos como o tempo dos relógios e o espaço da geometria"25.

Assim se forma uma nova noção de tempo, que se coloca como invariante quântica e indefinidamente reprodutível das leis da natureza ${ }^{26}$. O tempo variável, torna-se, por assim dizer, o produto historicizado de funções de coordenação que o sujeito do Cogito, sede da Consciência, lhe impõem, e onde instrumentos de medida se tornaram possíveis pela démarche simbólica de intervalos vazios e opacos, unificados formalmente pelo pensamento científico agnóstico.

O Tempo se configura numa atividade humana que consiste em "fazer o tempo", associando-se ao princípio fundamental de conquista do mundo, isto é, ele varia segundo os parâmetros relativos do estudo da extensão da matéria e a cronologia existencial da vida, alinhados historicamente. Decifrar o tempo não contempla mais um ato gnóstico, ao integrar

\footnotetext{
${ }^{23}$ Expressão empregada por G. DURAND, 1979, op. cit.

${ }^{24}$ Cf. G. DURAND. 1979: 20.

${ }^{25}$ Cf. G. DURAND, 1979: 41

26 DOSSE. 1996. Cf. comentários P. RICOEUR, 1994, o tempo regulado do calendário torna-se o, enfim, intermediário entre o tempo vivido e o tempo cósmico. Essa modalidade simbólica de controle de tempo, o calendário, cosmologiza o tempo vivido e humaniza o tempo cósmico.
} 
um pensamento simbólico que adere simpaticamente as coisas e aos lugares, na busca do desvendamento de seu sentido. ${ }^{27}$

Sob o signo do esfacelamento da gnose do tempo tanto quanto da gnose do espaço, desfigura-se progressivamente não apenas a figura do homem, mas a função fantástica da memória, "reserva infinita de eternidade contra o tempo" 28 , reduzida à condição instrumental, sujeita ao dinamismo da consciência ou a condição de imagem miniatura do mundo.

Tal é o estatuto que assume a memória sob o manto do Iluminismo ${ }^{29}$, ela diz respeito não mais as relações entre o homem e cosmos, mas ao Indivíduo que ascende, enfim, ao estatuto de um micro-universo, sujeito absoluto e autônomo da razão que atua no lugar do próprio tempo.

Sem dúvida, esse trajeto sinistro do "homem da civilização" 30 que negligencia à memória as propriedades de um espaço fantástico, onde a imaginação criadora pode dirigir suas obra contra a Morte e o Destino, não se afirmou como a absoluta vitória do tempo linear e progressista sobre outras modalidades simbólicas de controle do tempo na civilização do Ocidente extremo.

Assim, no séc. XIX, poetas, cronistas e memorialistas como Proust, Baudelaire, Valéry, entre outros, que aderiram aos encantos de Mnemosyne, à sua fascinação onírica, religiosa, estética ou patológica não tinham por intenção desafiar o ideal prometéico do progresso técnico da sociedade industrial e de suas esperanças messiânicas, tratava-se de proteger a consciência ocidental de suas contradições mais profundas.

Assim, as imagens noturnas e os mitos da intimidade e da introspecção, em fins do séc. XIX, tornavam-se o contraponto ao "culto da Razão", ao sujeito ético e moral da história, em sua luta heróica e diurna para domesticar o tempo e a morte, sob o ritmo dos relógios e dos apitos de fábricas, subjetiva noção de Indivíduo moderno. Ritmos reduzidos a um tempo homogêneo e indiferente, onde a duração de uma vida é medida em função de intervalos artificiais e unidades abstratas. Neste contexto, a memória transforma-se num eterno equívoco entre a face da natureza absoluta do sujeito individual. $\mathrm{O}$ conteúdo físico das histórias individual ou coletiva - o conteúdo de suas ações no mundo - desliga-se de seu receptáculo espaço-temporal (seus modos de pensamento), a tal ponto que o tempo psicológico,

\footnotetext{
${ }^{27}$ Cf. G. DURAND, 1979: 44.

${ }^{28}$ Cf. G. DURAND, 1984.

${ }^{29}$ DIAS DUARTE, 1983: 36 e 37.

${ }^{30}$ Segundo G. DURAND, 1979, Figures mythiques, op,. cit., o contraponto intimista se fazia sentir já no séc. XVIII no Iluminismo, com J.J. ROUSSEAU, face ao mito progressista que iria consumir lentamente o período pós-revolucionário, encontrando seu "refúgio" no séc. XIX, século do alcoolismo e do ideal heróico da produção industrial, e sua expressão decadente na atual sociedade de consumo, no séc. XX.
} 
indissociável das experiências mundanas entra numa espécie de anthroposiasmos ${ }^{31}$.

Portanto, através da supervalorização, a interioridade do tempo psicológico, a “ideologia moderna" atribui uma dimensão unificadora à consciência, delegando ao sujeito do Cogito a ação de mediar o tempo do mundo e dos acontecimentos ${ }^{32}$. Ao mesmo tempo, a ideologia moderna gera no seu ventre o culto romântico à memória não só como processo restrito a subjetivação do sujeito, mas como espaço de reinversão das situações e valores iniciais de um século de filosofias da história, de evolucionismo e de progressismos, tal qual aparece na obra de Baudelaire, comentada por Benjamin ${ }^{33}$.

\section{A dialética das "épistèmés" do Mesmo e do Outro}

Na pré-história da ciência antropológica, o quadro epistêmico do final do século XIX, foi rico em deslizar das estruturas elementares do evolucionismo para a gestação de uma nova concepção da pessoa no contexto da duração histórica. Da mesma forma, o pensamento da École de l'Année Sociologique, é fértil em exemplos a respeito das formas como o evento da natureza desliza da religiosidade para uma racionalidade e psicologização do sujeito, e a temporalidade cíclica, doravante, aprisionada por eventos históricos, aparece em momentos fugidios à consciência do coletivo social ${ }^{34}$.

Até agora foi traçado os schémas epistemológicos através dos quais as ciências humanas têm encontrado para operar o conhecimento sobre o fenômeno da memória e da temporalidade. Resta ainda lembrar alguns autores paradigmáticos que trataram de situar os estudos da memória para além dos ditames da Era moderna, na esteira de uma visão mais plena da figura do homem, e cujas proposições sempre serão lembradas nas diferentes reflexões de teoria antropológica sobre o devir. A lembrança dos ensinamentos destes mestres autoriza a própria memória das tradições e paradigmas antropológicos a se desvincularem da virulência de um positivismo e de um historicismo reducionistas.

A obra de Maurice Halbwachs (1877-1945) é certamente aquela que, mesmo herdeira

\footnotetext{
${ }^{31}$ A este respeito, L. DUMONT, 1970, fala de um anthroposiasmos, de uma 'possessão' por si mesmo ou pelo conceito do Indivíduo livre, autônomo e soberano. Cf. DIAS DUARTE, p. 40.

${ }^{32}$ Cf. DIAS DUARTE, p. 44: "Pode-se afirmar, com propriedade, que o historicismo, por exemplo, formulou os parâmetros de uma consciência, onde a memória assume uma posição externa e factual, Da mesma forma, a nascimento da psicanálise engendra-se no momento em que atribui ao inconsciente esta representação articulada sobre a interioridade."

${ }^{33}$ Cf. G. DURAND, 1979: 248, “os românticos misturam sempre o prometeismo dos Enciclopedistas e o misticismo do Iluminismo", assim, o mito romântico é “ um drama cuja resolução é o triunfo de um princípio: a morte de Satã".

${ }^{34}$ Cf. DIAS DUARTE. 1983: 35, “A imortalidade se desloca do eixo da preservação e cultivo da pessoa cognitiva para o da pessoa moral que se deveria justamente premiar na reintegração positiva na divindade após a morte".
} 
de uma linhagem sociológica, reina soberana em suas referências ao destino imemorial das sociedades humanas. Halbwachs, na aurora dos estudos sobre memória, rompendo com a influência do bergsonismo, vai conferir a tais estudos um tratamento conceitual mais complexo e sofisticado. Apegado aos valores de reconciliação que a memória confere ao homem e ao mundo, Halbwachs, reconhece, nos jogos da memória e nos seus enquadramentos com a vida, os seus atributos de um fenômeno social. Afasta-se, assim, do bergsonismo ao perceber a solidariedade entre o tempo e a matéria de seu conteúdo, instalando os jogos da memória no real; engendrado-os no interior do mundo social, as estruturas espaço-temporais das sociedades humanas adquirem espessura inusitada.

Para Halbwachs, as noções de tempo e espaço são estruturantes dos quadros sociais da memória, ambos instâncias solidárias, fundamentais para a rememoração do passado na medida em que as localizações espaciais e temporais das lembranças são a essência da memória ${ }^{35}$. Nada escapa, nem mesmo a memória, a esta trama sincrônica da existência social uma vez que é da combinação dos diversos elementos do mundo social que pode emergir a lembrança comunicada pela linguagem ${ }^{36}$.

Sem dúvida, o pensamento de Halbwachs almeja uma definição mais sofisticada das estruturas espaço-temporais na configuração das sociedades humanas; em tais estruturas o tempo não sofre de reducionismo, abrindo espaço para a compreensão da geografia fantástica que encerram dos trabalhos da memória. Ele reconhece a vibração do tempo no conteúdo material das lembranças, atribuindo à memória o princípio "intencional" e "imaterial” de uma coordenação entre as diferentes temporalidades e as regiões do espaço em que se produzem, pois as lembranças são solidárias das regiões de experiência, as quais, por sua vez, lhe são irredutíveis ${ }^{37}$.

Opondo-se a interpretação de um espiritualismo desusado que afirma que "a materialidade joga em nós os esquecimentos" e à concepção hegeliana de um devir único portador de uma lógica racional, a fecundidade do pensamento de Halbwachs frutifica em seu diálogo com a física einsteinianna ${ }^{38}$. Com ele, rompe-se a idéia distorcida da memória associada à ordem de um tempo psicológico, relativo ao seu conteúdo e indissociável dele,

\footnotetext{
${ }^{35}$ Cf. HALBWACHS 1968, o "esforço de rememorização cria um espaço e um tempo específicos", tal esforço significa que os sujeitos que lembram tempos e espaços singulares, os quais são da ordem da vivência. Trata-se, segundo o autor, da memória coletiva resgatada sobre acontecimentos vividos.

36 Através da memória coletiva compreende-se uma relação diferencial, "a sucessão de eventos individuais que resulta nas mudanças que se produzem nas nossas relações com os grupos os quais somos misturados e das relações que se estabelecem entre os grupos", cf. os comentários pertinentes de J. DUVIGNAUD, em seu prefácio à obra de M. HALBWACHS, 1968: XII.

37 Ver à propósito, os comentários de G. DURAND, 1984, em particular à obra de M. Halbwachs, 1941.

${ }^{38}$ Cf. J. DUVIGNAUD, "Préface". In. M. HALBWACHS, op. cit. P. XI.
} 
oposto a um tempo físico, concebido como espacializado e puramente formal, há ponto das velocidades das transformações da matéria não o atingir ${ }^{39}$.

A partir de Halbwachs, poder-se-ia dizer que o pensamento antropológico se reconcilia em parte, com a "figura do homem da tradição", pois segundo seu entendimento a lembrança do passado não é ato individual de recordar, mas o resultado de laços de solidariedade ${ }^{40}$. A memória, seguindo-se a sua inspiração, tem, portanto, uma dimensão intangível, porque simbólica, pelo segredo que carrega na conformação de uma tradição. A memória carrega consigo a dimensão profunda de mitos, lendas e crenças das sociedades humanas, as quais configuram as práticas ordinárias de seus grupos sociais.

Logo, os estudos de Halbwachs são, para seus herdeiros, um alerta! Eles apontam para as armadilhas epistemológicas que encerram uma "metafísica duvidosa" que enfoca a memória fora do contexto das manifestações culturais e sociais que configura a estética de seus arranjos, ou seja, as motivações simbólicas dos atores sociais que dela dispõem.

Nesta perspectiva, contemplar a memória significa reconhecer a força intangível das motivações simbólicas que regem as ações sociais humanas, o que significa que não se pode ignorar o espaço de figurações de utopias coletivas diferenciadas. Neste sentido, como muitos antropólogos ensinam ${ }^{41}$, a memória não se configura apenas num tradicionalismo de cunho nostálgico e sentimental, mas nos mitos, saberes, fazeres e tradições que são perenizados, ordinariamente, no interior das manifestações culturais humanas, à contragosto das intimações objetivas de um devir, "numa seqüência de fixações no espaço da estabilidade do ser."

Da mesma forma, as a̧ões discursivas que o próprio antropólogo faz acerca da memória enraízam-se no espaço dos mitos e das crenças da sociedade e do grupo social ao qual pertence. Voltando-se progressivamente as costas a dimensão intangível que configura a memória coletiva, social ou individual, o que resta para os estudiosos da memória no mundo contemporâneo, é a nostalgia das imagens: o fim das guerras, do fim das lutas, do fim dos tempos.

Como ensinam os estudos da cultura ocidental faustiana, nos dias atuais, a memória

\footnotetext{
${ }^{39}$ O belíssimo trabalho de Bosi, 1987, explorando o fértil pensamento de Halbwachs, nos revela a força da memória como ato de restaurar no presente as lembranças do passado, uma vez que lembrar não é reviver algo preservado do passado, mas é refazer, reconstruir, repensar com as idéias de hoje as experiências do passado.

40 A respeito, ver os comentários de E. BOSI 1987:17- 22, sobre o pensamento de Halbwachs quando afirma que este autor "amarra a memória da pessoa à memória do grupo, e esta última à esfera maior da tradição, que é a memória coletiva de cada sociedade". Segundo BOSI, rememorações cotidianamente construídas na dinâmica da vida pelo instrumento decisivamente socializador da memória: a linguagem pela qual se comunica o pensamento.

${ }^{41}$ A propósito ver, por exemplo, EVANS-PRITCHARD, E.E. 1978, GEERTZ, 1978, GURVITCH, G. 1961.

${ }^{42}$ Cf. G. DURAND, 1984.
} 
guarda sua expressão intangível em cidades mundiais que se exteriorizam numa expansão infinita, numa filiação arqueológica a arquitetura gótica e à perspectiva na arte renascentista, só para citar duas de suas filiações. Portanto, o estudo da memória, nos dias de hoje, não escapam à sua relação intima com a inteligibilidade dos símbolos e mitos criados pelas sociedades humanas. E no momento em que buscam ultrapassar a própria linguagem intangível de símbolos que constitui a própria humanidade, a memória nutre-se, ainda assim, da sua expressão social: o sentimento de anti-destino.

Assim, no corpo dos gestos fundadores do mundo contemporâneo, como em outros tempos, a memória autoriza a liberdade de criação humana uma vez que através dela valores, crenças, costumes e tradições perpetuam-se entre os grupos humanos que nela habitam; reservatório de símbolos e imagens a memória faz parte do gigantesco patrimônio da humanidade. À disposição de todos, a memória autoriza, de forma correlata, não só conflito de liberdades e sua afirmação, mas as trocas sociais e simbólicas que nela existem.

A partir de Halbwachs, poder-se-ia dizer que o "esquecimento", a "nostalgia", a "tragédia da cultura", a "crise da civilização", temas caros a autores tão diferentes como Benjamin, Baudelaire, Simmel et Splenger, são sentimentos tributários do corpo de tradições e crenças do patrimônio cultural legado pela Era moderna, eles próprios narradores de uma "memória épica" que busca a redenção dos mitos, lendas, crenças e valores ético-morais que caracterizaram a idéia de uma conquista progressiva da autonomia moral do Sujeito humano e que, por sua vez, não se esgotam nas formas do individualismo que herdamos da época da Luzes.

Neste ponto, é importante reter o que o estudo da memória ensina a todos que com ela operam: uma repulsa a um pensamento que separa o "eu" que pensa da compreensão daquilo que é pensado, pois, no limiar da memória há, sempre e eternamente, uma elaboração ética progressiva da vida social e da figura de homem. Habitar o espaço da memória é conviver com memórias coletivas, individuais e sociais negociadas, e não, simplesmente, domesticar um território vazio e opaco, lugar de reativação de tradições perdidas ou da nostalgia do passado.

Isto conduz a uma dialética suis generis na forma como é possível se operar com a dimensão ética e estética dos estudos da memória (valores, crenças, tradições, visões de mundo e estilos de vida diferenciais): pensar a sociedade contemporânea como reservatório concreto e efetivo de memórias coletivas e de vontades de indivíduos e grupos que, compartilhando um mesmo território plural de existência, agem em conjunto e reinventam quotidianamente a sua condição humana primordial, na busca de se eternizar no tempo. 


\section{BIBLIOGRAFIA}

BACHELARD, G. 1989 La dialectique de la durée. Paris, Quadrige/PUF (1ed 1950). BENJAMIN, Walter. 1990 "Sobre alguns temas em Baudelaire". In: Charles Baudelaire um lírico no auge do capitalismo. Obras escolhidas volume III. SP, Ed. Brasiliense.

BERGSON, Henri. 1990 Matéria e Memória. S.P. Martins Fontes.

BERMAN, Marshall. 1986 Tudo que é sólido desmancha no ar. A aventura da modernidade. São Paulo, Companhia das Letras.

BOLLE, Willi. 1994 Fisiognomia da Metrópole Moderna; representação da história em Walter Benjamin. São Paulo, Ed. USP.

BORELLI, Silvia Helena Simões. 1992 "Memória e temporalidade: diálogo entre Walter Benjamin e Henri Bergson". In: Revista Margem. Faculdade de Ciências Sociais - PUC - SP.

BOSI, Ecléa. 1987 Memória e sociedade. Lembranças de velhos. São Paulo, Queiroz ED. Ltda. e EDUSP.

CASSIRER, E. 1994 "O mundo humano do espaço e do tempo", In: Ensaio sobre o homem, introdução a uma filosofia da cultura humana. São Paulo, Martins Fontes.

DIAS DUARTE, Luiz Fernando. 1983 A Construção Social da Memória Moderna. In "Três ensaios sobre pessoa e modernidade". In. Botetim do Museu Nacionat, nova série, Rio de Janeiro, Antropologia, $\mathrm{n}^{\circ} 41$.

DOSSE, François. 1996 "Paul Ricoeur revoluciona a escrita da história"; In: Revista Margem, Temporalidades. Faculdade de Ciências Sociais - PUC, SP, número 5.

DURAND, Gilbert. 1979 Science de l'homme et tradition. Paris, Berg International Editeurs. DURAND, Gilbert. 1984 Les structures anthropolgiques de l'imaginaire. Paris, Duond. DURAND, Gilbert. 1979 Figures mythieus et visages de l'ouvre. Paris, Berg International. ELIADE, Mircea. 1992 "A regeneração do tempo" IN: Mito do Eterno Retorno. SP, Mercuryo, P. 55 a 88.

ELIAS, Norbert. 1984 Du temps. Paris, Fayard, 1996 ou Über die Zeit..

EVANS-PRITCHARD, E.E. 1978 Os Nuer. São Paulo, Perspectiva.

GEERTZ, Clifford. 1978 "Pessoa, tempo e conduta em Bali" In: A interpretação das culturas. Rio de Janeiro, Zahar. 321 p.

GURVITCH, G. 1961 La multiplicité des temps sociaux. Paris, Cours de la Sorbonne,. HALBWACHS, Maurice. 1968 Mémoire Collective. Paris, P.U.F. $2 \mathrm{O} 4$ p.

HOBSBAWN, Eric \& RANGER, Terence. , 1984 A invenção das tradições. Rio de Janeiro, Paz e Terra.

JEUDY, HenriPierre. 1986 Mémoires du Social. Paris, P.U.F. 171 p.

LE GOFF, J. NORA, P. 1987 Les lieux de la mémoire (volumes 1,2,3). Paris, Gallimard. LE GOFF, Jacques. 1990 História e memória. Campinas, ED. Unicamp.

NAMER, Gérard. 1987 Mémoire et Société. Paris, Méridiens Klincksieck. 242 p.

POLLAK, Michael. 1989 "Memória, esquecimento, silêncio" In: Estudos Históricos 3, Memória. Rio de Janeiro, vol. 2, n. 3, p. 3 a 15.

RICOEUR, P. 1994 Tempo e Narrativa. Volumes I, I e III. São Paulo, Papirus.

RICOEUR, P. et alii.1979 El tiempo y las filosofías. Paris, Unesco/ Salamanca, Ediciones

Sígueme.

SAHLINS, Marshall. 1990 Ilhas da Historia. Rio de Janeiro, Jorge Zahar.

SANTOS, Myrian. outubro de 1993 "O pesadelo da amnésia coletiva, um estudo sobre os conceitos de memória, tradição e traços do passado. "In Revista Brasileira de Ciências Sociais, n 3, ano, ANPOCS 23.

THOMPSON, Paul. 1992 A voz do passado. Historia Oral. Rio de Janeiro, Paz e Terra. 